NBER WORKING PAPER SERIES

\title{
INSTITUTIONS AND CONTRACT ENFORCEMENT
}

\author{
Armin Falk \\ David Huffman \\ W. Bentley MacLeod \\ Working Paper 13961 \\ http://www.nber.org/papers/w13961
NATIONAL BUREAU OF ECONOMIC RESEARCH
1050 Massachusetts Avenue
Cambridge, MA 02138
April 2008

We are grateful for helpful comments from seminar participants at IZA Bonn, the University of Zurich, Columbia University, the NBER summer institute, and the Wharton School of Business. The views expressed herein are those of the author(s) and do not necessarily reflect the views of the National Bureau of Economic Research.

NBER working papers are circulated for discussion and comment purposes. They have not been peerreviewed or been subject to the review by the NBER Board of Directors that accompanies official NBER publications.

(C) 2008 by Armin Falk, David Huffman, and W. Bentley MacLeod. All rights reserved. Short sections of text, not to exceed two paragraphs, may be quoted without explicit permission provided that full credit, including $(\subset$ notice, is given to the source. 
Institutions and Contract Enforcement

Armin Falk, David Huffman, and W. Bentley MacLeod

NBER Working Paper No. 13961

April 2008

JEL No. C9,D01,J3,J41

\begin{abstract}
$\underline{\text { ABSTRACT }}$
We provide evidence on how two important types of institutions -- dismissal barriers, and bonus pay -- affect contract enforcement behavior in a market with incomplete contracts and repeated interactions. Dismissal barriers are shown to have a strong negative impact on worker performance, and market efficiency, by interfering with firms' use of firing threat as an incentive device. Dismissal barriers also distort the dynamics of worker effort levels over time, cause firms to rely more on the spot market for labor, and create a distribution of relationship lengths in the market that is more extreme, with more very short and more very long relationships. The introduction of a bonus pay option dramatically changes the market outcome. Firms are observed to substitute bonus pay for threat of firing as an incentive device, almost entirely offsetting the negative incentive and efficiency effects of dismissal barriers. Nevertheless, contract enforcement behavior remains fundamentally changed, because the option to pay bonuses causes firms to rely less on long-term relationships. Our results show that market outcomes are the result of a complex interplay between contract enforcement policies and the institutions in which they are embedded.
\end{abstract}

Armin Falk

Department of Economics University of Bonn

Adenauerallee 24-42, 53113 Bonn

armin.falk@uni-bonn.de

David Huffman

Department of Economics

500 College Avenue

Swarthmore, PA 19081-1397

dhuffma1@swarthmore.edu
W. Bentley MacLeod

Department of Economics

Columbia University

420 West 118th Street, MC 3308

New York, NY 10027

and NBER

bentley.macleod@columbia.edu 


\section{INTRODUCTION}

This paper uses experimental labor markets to study how two important, and often controversial, institutions - dismissal barriers, and bonus pay - affect contract enforcement behavior. We focus on a setting with incomplete contracts as this is a ubiquitous characteristic of employment relationships. ${ }^{1}$ We also allow for repeated interactions, because a prominent theoretical solution to the contract enforcement problem associated with incompleteness involves employers and employees interacting in a repeated game. In particular, the theory involves employers using a combination of rents and threat of dismissal to give workers an incentive to perform (e.g., Klein and Leffler (1981), Shapiro and Stiglitz (1984) and MacLeod and Malcomson (1989)).

Dismissal barriers are a particularly important institution to study in the context of incomplete contracts, given the strategic importance of firing threat in such settings. Dismissal barriers have the potential to radically change the strategic interaction of firms and workers within relationships, as well as patterns of relationship formation in the market. Dismissal barriers arise, for example, in the presence of employment protection legislation (EPL), where hiring a worker beyond a probation period triggers barriers to dismissal, or in the case of relationship-specific investments that accrue over time and raise firing costs (see Mincer (1962))

The flexibility of the labor contract is also a key institutional feature, in particular whether firms are restricted to the wage contract focused on in the efficiency wage literature, or whether contractual instruments such as bonus pay or other forms of delayed compensation are also available. Previous evidence indicates that bonus pay is a credible incentive device in one-shot games, because firms reward performance with bonuses, and punish shirking by

\footnotetext{
${ }^{1}$ See Williamson, Wachter, and Harris (1975) for a classic early study.
} 
withholding the bonus (Fehr, Gächter, and Kirchsteiger (1997); Fehr, Klein, and Schmidt (2007)). The availability of bonus pay thus has the potential to fundamentally change firms' contract enforcement policies in a repeated game setting. Furthermore, the availability of bonus pay may be crucial for determining the impact of dismissal barriers, to the extent that it provides firms with an alternative incentive device to threat of firing.

We begin by establishing a baseline condition (T-Baseline) in which there are no dismissal barriers and no bonus pay. We use as our workhorse the experimental framework of Brown, Falk, and Fehr (2004), in which firms and workers can endogenously form long-term relationships. Firms offer contracts involving a wage and a desired effort, and after accepting a contract workers choose their effort level, which is unenforceable.

Despite the contract enforcement problem, effort levels in T-Baseline are on average quite high. High efforts are observed mainly in long-term relationships. This reflects a policy of firms paying rents relative to unemployment, and credibly firing poor performers. These findings corroborate those of Brown, Falk, and Fehr (2004), and show the central importance of firing threat as an incentive device. This sets the stage for exploring our main research questions.

We implement a second treatment (T-Barrier) in which there is a dismissal institution present in the market, such that only the worker can end a relationship once the firm chooses to hire the worker two times in a row. The first time a firm hires a worker thus corresponds to a "probation" period, in which firing is still possible. Firms are also restricted in their ability to lower wages once they trigger dismissal protection by engaging in the second consecutive contract, to rule out de facto dismissal by reducing wages to zero. ${ }^{2}$

We predict three main effects of the dismissal barrier institution. The first is a negative incentive effect, due to removal of firing threat as an incentive. Consistent with this ${ }^{2}$ Most legal jurisdictions view the reduction of wages to zero as equivalent to firing a worker. 
prediction, average effort levels in long-term relationships are far below those observed in the baseline condition, which also leads to lower market efficiency. A second prediction is a probation period effect, such that worker effort is especially high in the probation period, due to the added attractiveness of enticing firms into long-term relationships, and then drops sharply once the worker is re-hired. Indeed, this pattern is pervasive in T-Barrier, whereas in the baseline condition the opposite pattern is observed. The third prediction concerns a set of related effects on relationship-formation: firms are predicted to be more reluctant to enter relationships in a market with dismissal barriers, because of the incentive problem; the prediction for turnover is ambiguous, because the tendency to engage in more one-shot interactions is potentially offset by the tendency for relationships that do form not to break up; dismissal barriers are predicted to have a systematic effect on the shape of the distribution for relationship lengths in the market, leading to more very short and also more very long relationships. Observed behavior is supportive of all these relationship formation effects.

In a third treatment (T-Barrier-Bonus) we implement both dismissal barriers and the option for firms to offer contractually non-enforceable bonuses as part of the initial contract. After observing worker performance, firms can decide how much of a bonus to actually pay.

The impact of dismissal barriers is dramatically altered by the presence of bonus pay. Firms credibly reward worker performance by paying bonuses, and this additional incentive device essentially eliminates the problem of worker shirking in long-term relationships, despite the absence of firing threat. Market efficiency is also substantially improved, and the probation period effect on effort dynamics disappears. Relationship formation remains significantly different from baseline, however, with firms being less prone to enter relationships, despite the fact that worker performance in long-term relationships is no worse than in the baseline condition. One potential explanation for this latter finding is that bonus pay causes 
firms to rely less on relational incentives in general, because bonus pay and relationships act as substitute incentive devices. This latter explanation cannot be verified without introducing a fourth treatment, where there is bonus pay but no confounding effect of a dismissal institution.

We briefly investigate behavior in such a treatment (T-Bonus). Firms are much less prone to initiate long-term relationships when bonus pay is available, compared to the case where there is no bonus pay, indicating that bonus pay and relational incentives are in fact substitutes. Interestingly, T-Bonus also shows that in the absence of dismissal barriers bonus pay does not have a strong advantage over wage contracts as a way of eliciting worker performance. In the absence of dismissal barriers, the additional option to pay bonuses improves market efficiency only marginally compared to a case (T-Baseline) where firms must rely on the combination of wages and firing threat.

Taken together, the findings shed light on how enforcement behavior interacts with the surrounding institutional environment. The negative incentive effect of dismissal barriers depends on the flexibility of the contracting technology, but while introducing contractual flexibility reduces negative efficiency consequences, in other ways contract enforcement strategies are left fundamentally changed. Though institutions impose constraints on contract enforcement strategies, agents are not passive, but respond by finding different avenues for solving incentive problems. In other words, understanding strategic interactions within firms requires an appreciation of the institutions in which contractual relations are embedded, and at the same time, understanding the impact of institutions requires an appreciation of how they interact with details of firms' contract enforcement strategies.

Substantial progress has been made in previous theoretical work on the interplay of contract enforcement and institutions, in settings with repeated interactions. Beginning with 
Telser (1980), there have been a number of contributions that use repeated game theory to model the enforcement of incomplete contracts. Klein and Leffler (1981), Shapiro and Stiglitz (1984) and Bowles (1985) show that the use of a high wage with the threat of firing can ensure performance. Bull (1987) and MacLeod and Malcomson (1989) introduce bonus pay to the model, and show that a similar result holds, while Levin (2003) extends these models to allow for asymmetric information in addition to contract incompleteness. These papers restrict attention to the case of risk neutral agents, for which bonus pay does not typically play a substantive role in ensuring efficiency. Rather, in the spirit of the folk theorem (Fudenberg and Maskin (1986)), there are many possible efficient equilibria. What bonus pay does is affect the distribution of the surplus between the worker and the firm. ${ }^{3}$

MacLeod and Malcomson (1998) show, in contrast, how the division of surplus can have efficiency consequences, depending upon the relative supply of workers and capital. In particular, when capital is in short supply, then it is efficient to have it fully utilized, which is possible under an efficiency wage contract, but not under a bonus pay contract. Our experimental market corresponds to the case of a shortage of capital, given that the number of jobs is always less than the number of workers. Thus, the theory predicts that the equilibrium with efficiency wage contracts should be much more efficient, whereas we find that both wage contracts and bonus contracts yield similar performance (in the absence of barriers).

There are a number of reasons why standard theory does not explain our results. First, it is assumed that agents are infinitely lived, while in practice and in our experiments all relationships are necessarily of finite duration. Without additional assumptions, all of these theories predict a dismal level of minimum efficiency in all of our treatments, due to standard

\footnotetext{
${ }^{3}$ Baker, Gibbons, and Murphy (1994) show that bonus pay has an important impact on surplus when the firm also has available objective measures of performance. Pearce and Stacchetti (1998) extend these results to the case of risk averse agents.
} 
backwards induction arguments. From previous experimental evidence on contract enforcement behavior (e.g., Fehr, Kirchsteiger, and Riedl (1993); Fehr and Falk (1999)), however, it is known that in practice non-minimal efficiency is typically achieved even in one-shot interactions with incomplete contracts. Beginning with Kreps, Milgrom, Roberts, and Wilson (1982), it is well know that such behavior is consistent with the hypothesis that individuals have social preferences that incorporate factors other than the pecuniary returns from a decision. The difficulty is that we do not have an established model of these preferences, and hence as Fehr, Klein, and Schmidt (2007) observe, it is necessary to use experimental evidence to uncover how specific institutions will work with human subjects.

There are previous experimental studies on contract enforcement behavior, but to our knowledge none on the important topic of how dismissal barriers affect contract enforcement, or on how the impact of dismissal barriers depends on other institutional features, such as availability of bonus pay. This is partly because until recently experimental studies have focused almost exclusively on static settings, whereas studying the incentive effects of dismissal barriers requires a setting with repeated interactions by its very nature. ${ }^{4}$ Although the focus of our paper is on the interaction of dismissal barriers and bonus pay, our results also complement the experimental literature studying the question of how bonus contracts perform relative to wage contracts. Fehr, Gächter, and Kirchsteiger (1997) and Fehr, Klein, and Schmidt (2007) find that bonus contracts perform much better than wage contracts in terms of efficiency, in one-shot interactions. Our results qualify these findings somewhat, showing that in a repeated game setting bonus contracts perform only slightly better than wage contracts, with the difference narrowing over time. The key difference is that in repeated game settings firms can combine wage contracts with threat of firing, whereas in

\footnotetext{
${ }^{4} \mathrm{Wu}$ and Roe $(2007)$ also use the repeated-interaction framework of Brown, Falk, and Fehr (2004), but focus on varying the degree of incompleteness in contracts.
} 
one-shot games worker performance under a wage contract depends solely on altruistic or reciprocal motives of the worker. On the other hand, our findings show that bonus pay does have large benefits relative to wage contracts, even in repeated game settings, if there are some barriers to dismissal in the market.

The rest of the paper is organized as follows. Section 2 describes the experiment, and Section 3 outlines predictions for behavior. Section 4 presents results, and Section 5 concludes.

\section{THE EXPERIMENT}

2.1. Design. The labor market operated for 18 trading periods. In each period a firm could hire at most one worker, and a worker could have at most one job. An individual period involved two or three phases, depending on the treatment. The first phase was always a market phase, in which the firms made contract offers and workers could only accept or reject. Firms could make as many contract offers as they wanted during the time limit of three minutes; if one of a firm's contracts was accepted, all of the other offers by that firm were immediately removed from the market. ${ }^{5}$ In the case that a firm and a worker agreed on a contract, they entered a second phase in which the worker could decide how much effort, $e$ to exert. In treatments where the contract offer could include an offered bonus, there was a third phase in which the firm was informed about the worker's effort choice and could decide how much of a bonus, $b$, to pay. Importantly, neither the worker's effort level or the firm's bonus payment were restricted by the initial contract agreement, whereas a wage specified in the agreement was binding. After the second (third) phase, the firm and worker were informed about their profits and earnings, respectively, and then a new period began.

${ }^{5}$ If all firms had contracts, there was no potential for further trades. Thus, the market phase was designed to end automatically after three minutes, or after the last firm had a contract offer accepted, whichever came first. 
Contract offers consisted of a wage, $w$, a desired effort level, $\tilde{e}$, and in some treatments an offered bonus, $\tilde{b}$. The offer also included the firm's ID number. Firms could make two types of contract offers during the market phase: public offers or private offers. Public offers were observed by all workers, and thus could be accepted by any worker. Private offers were observed only by a worker specified by the firm, and thus were available only to that particular worker. In the case that a firm made a private offer, the firm specified a worker's ID number, in addition to the contract terms. Worker and firm ID numbers remained constant over the entire 18 periods, so it was possible for a firm to intentionally make a private offer to the same worker over multiple periods, and for a worker to recognize offers coming from a specific firm. This design made it possible for a firm and worker to endogenously form a long-term relationship, by choosing to repeatedly engage in private-offer contracts with each other over multiple periods. Public offers were a way for firms to engage in a spot market for labor rather than engaging in long-term relationships. During the market phase, firms were kept constantly informed about which workers had already accepted a contract, so as to avoid having firms make a private offer to a worker that was no longer available.

In treatments with the dismissal barrier institution, a firm lost the ability to fire a worker in the case that in two consecutive periods the worker had accepted a private offer from that firm. In other words, if a worker accepted a private offer from a firm in period $t$, and then accepted a second private offer from the same firm in period $t+1$, the dismissal barrier took effect and only the worker could then end the relationship. In our experiment we thus effectively set the cost of firing to infinity. Disallowing firing, as opposed to introducing an additional parameter capturing a finite cost of firing, has the advantage of simplifying an already complex choice situation. It also provides a particularly tough test of the ability of bonus pay to overcome the effects of dismissal barriers. The fact that the dismissal 
barrier was activated only with the second consecutive contract captures a common feature of EPL institutions, which is an initial probation period, during which the firm is still able to fire the worker. It also has an analogue in situations where there are relationship-specific investments that increase firing costs, but where investments are made only after an initial probation period.

Having chosen to hire the worker again, after the initial private offer, the dismissal barrier took effect and the firm had to make an offer to that same worker at the beginning of each subsequent period until the end of the game or until the worker decided to reject the firm's offer. Firms who had chosen to trigger the dismissal barrier made subsequent offers to the same worker in a special phase before the market phase. Importantly, once the dismissal barrier was activated, the wage offer had to be at least as high as in the previous period. Some rigidity of the wage is required for a dismissal protection institution to work, otherwise a firm could effectively fire a worker by reducing the wage to zero. ${ }^{6}$ After firms had made their offers required by the dismissal barrier institution, the market period began and workers protected by the dismissal barrier could see the standing offer from their own firm, in addition to the other market activity. At any time, the worker could accept the standing offer, in which case the firm was informed. Alternatively, the worker could reject the offer by accepting another contract in the market. As soon as the worker rejected the standing offer, the firm was informed, and allowed to make offers during the remainder of the market phase.

In our design the effort cost function for workers, described below, is the same across all individuals so there are no differences in ability. This allows us to focus on the moral hazard problem in terms of effort and bonus payment, without the complication of adverse selection in terms of ability. We also do not implement cyclical shocks to market conditions,

\footnotetext{
${ }^{6}$ This is known as constructive dismissal, and is considered illegal in any jurisdiction with employment protection. See Black's Law Dictionary.
} 
or worker redundancies (multiple workers at one firm). This simplifies an already complex inter-temporal choice environment, and makes it possible to first understand the impact of dismissal barriers on the strategic behavior surrounding the contract enforcement problem.

We implemented four treatments, as summarized in Table 1. In a treatment called TBaseline, contracts consisted of a binding wage, $w$, and a desired effort level, $\tilde{e}$. There was no dismissal barrier institution in the market, so firms could engage in as many private offers in a row with a worker as they wanted, while always having the option to not re-hire the worker, i.e., not make the worker a private offer in the next period. ${ }^{7}$ In T-Barrier, contracts had the same form, but we introduced our dismissal barrier institution. In T-Barrier-Bonus,

the dismissal barrier institution was in effect, but firms had the option to offer a bonus, $\tilde{b}$, in addition to a wage. In T-Bonus, there was no dismissal barrier, but firms had the option to offer bonuses.

\subsection{Parameters, Information Conditions, Procedure, and Subject Pool. All mar-} ket sessions lasted 18 periods, and had 7 firms and 10 workers. The material payoff to a firm was given by the function

$$
\pi_{f}= \begin{cases}10 \cdot e-w-b & \text { if a contract offer was accepted } \\ 0 & \text { if no contract offer was accepted }\end{cases}
$$

and the payoff function for a worker was given by

\footnotetext{
${ }^{7}$ This treatment is a replication of the ICF treatment Brown, Falk, and Fehr (2004), except that their design involved only 15 trading periods rather than 18 .
} 


$$
\pi_{w}= \begin{cases}w+b-c(e) & \text { if a contract offer was accepted } \\ 5 & \text { if no contract offer was accepted }\end{cases}
$$

where $c(e)$ was a cost of effort function, and 5 was the unemployment benefit in the case that a worker did not engage in a trade. The wage, the offered bonus, and the bonus actually paid, $b$, could each take on an integer value $0,1,2, \ldots 100$. The desired effort level and the actual effort level chosen by the worker, $e$, could take on integer values $1,2, \ldots, 10$. The effort cost function is shown in Table 2. The cost function is increasing and convex. Because the marginal cost of effort is at most 3 , while the marginal benefit to a firm is always 10, the efficient effort level is 10 .

Payoff functions for workers and firms, including the effort cost function, were common knowledge. Participants were aware that the market would last 18 periods. Reputations could form bi-laterally: firms learned about the effort choices of workers that they traded with, but did not observe effort choices or bonus decisions, in interactions that they were not a part of; workers learned about the bonus decisions of firms that they encountered, but not about worker effort choices or firm bonus decisions in other market interactions. Firms observed all public offers on the market during the market phase. Workers were informed not only about private offers they had received, but also about all public offers on the market.

The experiment was computerized using Z-Tree software (Fischbacher (2007)). There was an unpaid practice period before the experiment began, which consisted only of a market phase but not the subsequent effort or bonus phases, to give subjects experience with the process of making and accepting offers. After the practice period, the first period of the paid experiment began. At the end of each period, a subject's period profits were summarized, 
along with the profits of the trading partner in the case of a trade. Subjects were also reminded of the partner's ID number, the terms of the initial contract, the actual effort choice, and the actual bonus paid. Subjects could record this information on a separate sheet of paper, ensuring that subjects were fully informed about their own trading history over the course of the experiment. The experiment was framed neutrally, in terms of buyers and sellers rather than workers and firms. Effort was referred to as quality. This facilitates comparison with Brown, Falk, and Fehr (2004). who used the same neutral framing. Fehr, Klein, and Schmidt (2007) show, however, that whether one uses framing as buyers and sellers, or workers and firms, is irrelevant for behavior in this class of experimental market settings. Representative instructions are provided in an appendix at the end of the paper.

There were 408 participants in the experiment (see Table 1). We conducted six market sessions for each of the four treatments, for a total of twenty-four sessions. Subjects were students at the University of Bonn, from various fields of study. No subject participated in more than one session. On average, a session lasted roughly 100 minutes, and a subject earned 25 Euros (approximately 32 USD).

\section{PREDICTIONS}

If it is common knowledge that workers and firms are motivated only by their own material payoffs, then the prediction for behavior in T-Baseline involves a very inefficient outcome. Workers will choose $e=1$ in the final period, regardless of the agreed-upon contract $\{w, \widetilde{e}\}$. Firms will find it optimal in the final period to offer wages that just compensate the worker for the outside option. All seven contract offers will be accepted. By backward induction, the same outcome will be realized in all previous periods, with the small surplus generated by the workers' minimal effort being claimed entirely by the firms. 
If material self-interest of firms and workers is not common knowledge, however, predictions change dramatically. Brown, Falk, and Fehr (2004) show theoretically that a sufficient number of fair-minded subjects, who respond to generous wages with high effort even in the absence of strategic incentives to do so, is sufficient to sustain an equilibrium in which all workers provide high effort levels in early market periods, and only the fair workers provide non-minimal effort in the final market period. The key mechanism for eliciting high effort from selfish workers (selfish in the sense of caring only about own material payoffs) is the existence of a rent in the final period, which arises because the presence of some fair workers makes it profitable (and therefore credible) for firms to pay generous wages even when there is no prospect for future interactions. The possibility of a future rent, and the threat of firing, discipline even selfish workers in the second-to-last period. Because only the future rent matters for selfish workers' incentives, firms could be expected to pay a low or zero rent in period 17. Given the plausible belief that the lack of a rent in the current period signals that a firm will not pay a rent in the future, however, firms will have an incentive to pay a rent even in this period.

MacLeod (2007) observes that the key feature in this argument is the existence of some rent in the last period, which may also be generated by individuals who have taste for performing as promised. This implies that in the second to last period, regardless of one's type, there will be a gain from continuing the relationship. MacLeod (2007) shows that a backwards induction argument implies that one very quickly obtains performance that is close to the first best in earlier periods.

These observations lead to several qualitative predictions for contract enforcement behavior in T-Baseline. Firms are predicted to trade repeatedly with the same worker if he performed well in the past. For this reason firms will rely on private offers, because in the 
case of public offers firms make the offer available to all workers regardless of past performance. In order for the possibility of future interactions to provide an incentive, the firm will need to pay a generous wage that offers a rent relative to being unemployed, and thus workers are predicted to gain some of the surplus from trade. Some workers are predicted to perform well even in the final period, in response to a generous wage, reflecting fairness concerns. Other workers who are concerned only with material payoffs will imitate fair workers in early market periods, but will reduce effort to the minimum in the final market period when the threat of firing no longer has an impact. These predictions are part of a particular equilibrium, but it is well known that in repeated games there exists a plethora of equilibria (see, e.g., Fudenberg and Maskin (1986)). This highlights the need to perform an experiment, in order to determine which equilibrium is selected. Brown, Falk, and Fehr (2004) find empirical support for these predictions, and our analysis in T-Baseline replicates their results, setting the stage for answering our main research questions.

The first question is how a dismissal barrier institution affects contract enforcement behavior in a setting with incomplete contracts and repeated interactions. We identify three main predictions regarding the impact of dismissal barriers. The first prediction is a negative incentive effect: in long-term relationships, the dismissal barrier institution removes the threat of firing as an incentive device; as a result, selfish workers are predicted to shirk in long-term relationships in T-Barrier, leading to lower effort levels than in T-Baseline. The second prediction is a probation period effect: dismissal barriers are predicted to change effort dynamics, such that effort is especially high in the initial probation period, because workers have a greater benefit from entering long-term relationships, and then drops sharply once the firm commits do a long-term relationship, due to the removal of firing threat as an 
incentive. The third prediction concerns relationship formation effects. Firms face a distribution of worker types, some who perform in the absence of firing threat and some who do not, but the fact that average performance declines in long-run relationships is predicted to make firms more reluctant to enter long-term relationships in T-Barrier than in T-Baseline. The implication for the average length of relationships is ambiguous. Relationship avoidance creates a larger number of one-shot relationships, but dismissal barriers imply that relationships that do form are likely to be long lasting, because firms are unable to fire workers. The unambiguous prediction is a change in the distribution of relationship lengths, such that the distribution has more very short but also more long lasting relationships in T-Barrier.

The next question is how the impact of dismissal barriers interacts with the addition of bonus pay. In line with evidence from one-shot settings (Fehr, Gächter, and Kirchsteiger (1997)), firms are predicted to pay bonuses for performing workers, creating a credible incentive for workers to perform even in the absence of firing threat. As a result, firms are predicted to circumvent the negative incentive effect of dismissal barriers by using bonus pay, so that effort in long-term relations is higher in T-Barrier-Bonus than in T-Barrier. Furthermore, because incentives are high powered even after the probation period, there will be a less pronounced probation effect in T-Barrier-Bonus compared to T-Barrier. The prediction for relationship formation is ambiguous. On the one hand, firms should be less reluctant to enter relationships since the hold-up problem is mitigated. On the other hand they have another incentive tool at their disposal, and therefore may rely less on relational contracting in the first place.

This latter point raises the question how contract enforcement is affected by bonus pay in general, i.e., in the absence of dismissal barriers. Shorter relationships in T-Barrier-Bonus 
could reflect a general tendency for bonus pay to lead firms to substitute away from relational incentives. This cannot be answered by T-Barrier-Bonus, because of the confounding presence of dismissal barriers, and requires the fourth treatment T-Bonus. In the final results section we briefly discuss the impact of bonus pay per se on contract enforcement, compared to T-Baseline.

\section{Results}

4.1. Contract Enforcement in the Baseline Condition. To set the stage, we first study T-Baseline, where there is no dismissal barrier institution and no bonus pay. A first observation is that worker effort levels in T-Baseline are quite high, despite the fact that the sub-game perfect prediction for the stage game is an effort level of 1 . The modal effort level across all periods is 10 , the median is 7 , and the mean is 6.39 (these values are very similar to those obtained in Brown, Falk, and Fehr (2004)). The question then is how firms elicit relatively high worker effort levels, in spite of the contract enforcement problem.

One clue is that high effort levels are mainly observed in private offer contracts, which are typically part of long-term relationships. Long-term relationships arise when a firm and worker endogenously choose to engage in sequence of two or more consecutive private offer contracts with each other. Of all contracts, 67 percent are private offers, and of these roughly 64 percent end up being part of a relationship lasting at least 5 periods. The level of effort in a given interaction is also strongly predictive of the ultimate length of the relationship: the correlation between effort and ultimate length is 0.64 (Spearman; $p<0.001$ )

Figure 1 shows that high effort levels and long-lasting relationships go together, due to the contract enforcement strategy of firms: firms continue a relationship only in the case that the worker performed well in the previous period. For low effort levels, the probability that the firm terminates the relationship is close to 1 , and for the maximum effort level the 
probability is close to zero. We also estimated a Probit regression, where the dependent variable is 1 in the case a worker is not rehired with a private offer and zero otherwise, and find that the estimated impact of an additional unit of effort in the previous period on the probability of termination is -0.104 ( $p<0.001$; robust s.e., clustering on session).

[Figure 1 about here]

The policy of credibly punishing poor performance with termination provides a material incentive for workers to perform, if workers find continuing the relationship more attractive than the alternative. The alternatives are either accepting a public offer, if one is available, or unemployment. In fact, workers in private offer contracts earn 34.75 on average, compared to 24.06 in public-offer interactions, or 5 from being unemployed. A similar picture emerges when one considers the total rents from being hired with a private offer in a given market period. For each period $t$ we calculate a proxy for total rents by summing up current and future earnings, from $t$ to $T=18$, for all workers who are in a private offer contract in period $t$. We compare the average of this value for a given period, denoted $V_{\text {priv }}$, to the average current and future earnings of workers who are in a public offer contract in the same period, and workers who are unemployed, denoted $V_{p u b}$ and $V_{u}$, respectively. The differences $V_{\text {priv }}-V_{\text {pub }}$ and $V_{\text {priv }}-V_{u}$ are positive in every market period. Thus, threat of firing serves as a credible incentive device, because firing imposes a cost on workers in the form of foregone rents. Workers earn a sizable rent even in the final period, which is important for sustaining an equilibrium with high effort levels in early periods. Workers earn rents, despite putting in high effort, because firms pay substantially higher (efficiency) wages in long-term relationships: median wages are 55 in private offer contracts, compared to 30 in public offer contracts, or unemployment benefits of 5 . Long-term relationships are 
also profitable for firms. Average firm profits in private offer contracts are 29.84, compared to 13.05 in public offer contracts.

Underlining the importance of threat of firing, 58.33 percent of workers who are re-hired in the final period reduce effort relative to their effort in period 17 , and 35.71 percent choose an effort level of 1, despite having chosen an effort of 10 in the previous period. Firms reduce wages somewhat in the final period, perhaps anticipating this behavior, but there is a significant drop in effort, even controlling for differences in offered contract terms. ${ }^{8}$

A sub-sample of workers performs well in response to generous wages, even in the final market period. Regressing effort levels in the final period on wages yields a positive coefficient on wages of 0.185 , significant at the one percent level (interval regression; robust s.e., clustering on session). ${ }^{9}$ This behavior is consistent with previous evidence indicating that some individuals have reciprocal inclinations, rewarding generous wages with high effort, even in the absence of strategic considerations (for a review see Fehr and Gächter (2000)). Thus, although threat of firing is clearly important for motivating many of the worker subjects, for a sub-population fairness concerns are also relevant. The presence of such types is important for deriving the equilibrium described in Section 3.

In summary, firms use a combination of rents and threat of firing to solve the contract enforcement problem in T-Baseline, consistent with the disciplining version of efficiency wage theory (Shapiro and Stiglitz (1984)). At the same time, the findings are also supportive of the fairness version of efficiency wage theory (Akerlof (1982), Akerlof and Yellen (1990)), in the

\footnotetext{
${ }^{8}$ This result is based on using the sample of contracts concluded in period 17 and 18 , and regressing the difference in effort between period 18 and period 17 on a dummy variable for final period, wages, desired effort, and a constant. The OLS estimate for the final-period dummy is $-3.004(p<0.008$; robust s.e., clustering on session), indicating that effort drops significantly in period 18 relative to 17 , controlling for contract offers in period 17 and 18.

${ }^{9}$ For a discussion of interval regression, see footnote 9 below.
} 
sense that a sub-population responds to generous wages with high effort even without firing threat. These results provide a baseline for investigation of our main research questions.

4.2. Contract Enforcement and Dismissal Barriers. We now turn to how dismissal barriers affect the strategic interactions of workers and firms, in an efficiency wage setting. We compare behavior in T-Baseline to behavior in T-Barrier, exploiting the exogenous variation in the presence of a dismissal barrier institution across treatments, while the form of the labor contract (fixed wages and no bonus pay) is held constant.

The first way in which dismissal barriers are predicted to affect the equilibrium described in Section 3 is by creating a negative incentive effect, such that (self-interested) workers are more prone to shirk in long-term relationships. Long-term relationships are defined as interactions that involve at least two consecutive private offer contracts between the same worker and firm. Average effort in long-term relationships is 8.4 in T-Baseline but only 5.5 in T-Barrier, providing initial support for the prediction. This difference is highly statistically significant using each session as one independent observation (Mann-Whitney; $p<0.01) .^{10}$ Median efforts are also strikingly different, 10 and 5, respectively (MannWhitney; $p<0.012$ ). Figure 2 shows that the effort differences in long-term relationships are large and stable across market periods, with effort being lower in T-Barrier than in T-Baseline in every market period.

[Figure 2 about here]

Table 3 investigates this issue using regression analysis. The dependent variable in each column is worker effort in trades occurring as part of a long-term relationship, and coefficients are marginal effects from interval regressions, to account for the fact that the dependent

\footnotetext{
${ }^{10}$ All non-parametric tests in the analysis take one session to be an independent observation.
} 
variable is measured in intervals and thus is left and right censored. ${ }^{11}$ Standard errors are robust, and are adjusted for clustering on session to account for possible correlation of error terms within a given session. ${ }^{12}$ In Column (1), we regress effort on a dummy for T-Barrier and a constant (omitted category is T-Baseline). The coefficient on the treatment dummy is negative and highly significant, indicating that dismissal barriers lead to lower effort levels in long-term relationships. The treatment effect remains negative and significant in Column (2) where we control for other factors that might affect effort: wages, desired effort, and a time trend.

[Table 3 about here]

If the drop in effort reflects the removal of firing threat as an incentive device, we should observe less of a difference in one-shot interactions, where the institution does not affect ability to dismiss poor performers. Estimating similar regression to those in Table 3, but using worker effort decisions in one-shot interactions (public offer, or private offer contracts that are not renewed), we do not observe a deficit in T-Barrier effort levels relative to TBaseline. In fact, effort levels are somewhat higher in one-shot interactions in T-Barrier than in T-Baseline. Later in the analysis we turn to possible reasons for the even better performance of workers in one-shot interactions in T-Barrier. The important point for the issue at hand is that effort levels are lower in T-Barrier precisely in situations where the

\footnotetext{
${ }^{11}$ The interval regression procedure maximizes a likelihood function that is a natural generalization of a Tobit, treating each value as a left and right censored observation coming from an interval with known bounds. Error terms are assumed to be normally distributed. For more information, see the STATA reference manual on the intreg procedure listed under Tobit estimation. We find similar results if we instead estimate regressions using OLS.

${ }^{12}$ In this and other regressions, our conclusions are similar if we do not adjust for clustering, although standard errors are typically smaller and effects are even more significant.
} 
institution makes a difference for firing threat, consistent with the negative incentive effect prediction.

It is noteworthy that aggregate efficiency is substantially lower in T-Barrier than in TBaseline, indicating that the negative incentive effect in long-term relationships dominates any tendency for dismissal barriers to enhance performance in one-shot interactions. Figure 3 shows the total economic surplus generated by trades in a given market period (averaged across sessions), relative to the maximum possible surplus. ${ }^{13}$ Whereas efficiency is 63.86 percent of the maximum in T-Baseline overall, efficiency is substantially lower in T-Barrier, about 52 percent, and the difference is growing over time. Starting around period 6, efficiency in T-Baseline begins to climb steeply, as relationships begin to form, and leaves efficiency in T-Barrier behind. From period 10 through 17, for example, efficiency in T-Baseline is about 19 percentage points, or 34 percent, higher than in T-Barrier (Mann-Whitney; $p<0.05$ ).

[Figure 3 about here]

Result 1: In a market with wage contracts, dismissal barriers cause significantly lower worker effort levels in long-term relationships, and lower market efficiency.

The next prediction concerns the dynamics of worker effort provision. The dismissal barrier institution prevents firms from using the threat of firing once a firm chooses to extend the relationship beyond the initial private offer contract, which we refer to as the "probation" period. Workers are predicted to sharply reduce effort relative to performance in the probation period, as soon as they are offered and accept a second private offer in a row from the same firm. This behavior would also shed further light on the negative

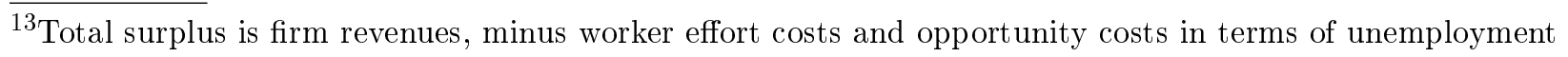
benefits. With 7 firms in each session, the maximum possible surplus in a period is equal to $7 \cdot(10 \cdot 10-18-5)=$ $77 \cdot 7=539$.
} 
incentive effect of the dismissal institution, by confirming that the lower effort levels in longterm relationships in T-Barrier reflect a within-individual moral hazard response, rather than other potential factors, for example a different composition of types who end up in long-term relationships in T-Barrier.

The probability of an effort drop is much larger in T-Barrier than in T-Baseline, and the size of the difference is also larger, supporting the prediction. The unconditional probability that a worker reduces effort in the second period of a relationship is 0.54 , compared to 0.23 , in T-Baseline. Furthermore, the average drop is equal to -1.57 in T-Barrier, while the average change in effort is actually positive in T-Baseline, equal to 0.11.

Figure 4 compares median effort, and also the distribution of effort, before and after the probation period. The sample is restricted to individuals who are ultimately rehired after the probationary period, so results for probationary and all later periods are based on the same sample of individuals. The boxes indicate the inter-quartile ranges $(25$ th to 75 th percentile) of the effort distributions, and the circular markers indicate the median effort levels. In T-Barrier, median effort drops sharply in later relationship periods relative to the probation period, and there is a substantial increase in the variance of effort. The opposite pattern is observed in T-Baseline. Results are similar if we instead compare effort in the probation period to effort in the second period of relationships only; the drop in effort in T-Barrier is immediate, occurring as soon as the probation period is passed, whereas effort increases in T-Baseline (see also Table 4, where we focus on comparing effort in the second relationship period to effort in the probation period). Thus, dismissal barriers lead to a post-probation-period drop in median effort, and an increase in effort variance in long-term relationships. 
The distribution in Figure 4 also reveals that there are still some workers in T-Barrier who choose close to maximum effort. This is consistent with the presence of some fair types who perform well even when dismissal barriers eliminate firing threat.

[Figure 4 about here]

Table 4 investigates the probation period effect on effort dynamics using regression analysis. The sample comprises all private-offer contracts taking place in the second period of a long-term relationship. The dependent variable in each column is equal to 1 if effort dropped relative to the first period of the relationship, and zero otherwise. Coefficients are marginal effects. Column (1) indicates that the probability of effort dropping is significantly larger in T-Barrier compared to T-Baseline, and Column (2) shows that this is still true conditioning on characteristics of the previous period interaction, and the contract terms in the current period, as well as a time trend.

[Table 4 about here]

Dismissal barriers are also predicted to have an impact on the level of effort in the initial probation period, because workers are willing to work even harder to entice the firm into making a second private offer. This motivation comes from the fact that workers anticipate enjoying a stronger strategic position once they get to enter a long-term relationship. Returning to Figure 4, it is evident that median effort is in fact higher in the probation period in T-Barrier, compared to the initial period of a relationship in T-Baseline. An interval 
regression using only initial private offer contracts that subsequently lead to long-term relationships shows that the effort level is higher by 0.629 points on average after controlling for wages, desired effort, and a time trend ( $p<0.017$; robust s.e., clustering on session). ${ }^{14}$

This suggests that dismissal barriers might also affect the type of workers who enter longterm relationships. For example, workers who are strategic and motivated only by material payoffs might be better at signaling to firms during the probation period that they have an intention to work hard in long-term relationships. One way to assess the proportion of selfish versus fair types who end up in long-term relationships is to look at the sensitivity of effort levels to wages in the final market period. The greater the fraction of selfish workers, the less sensitive effort should be to high wage offers. Using all private offer contracts in the final period, which were part of an on-going relationship in the previous period, we regressed effort on wages (interval regression; robust s.e. clustering on session). The impact of wages is positive but not significant in T-Barrier $(p<0.124)$, whereas the impact of wages on and significant in T-Baseline $(p<0.001) .{ }^{15}$ Thus, there is some suggestive evidence of a type of adverse selection, in terms of worker propensity to shirk, despite the fact that cost functions are held constant and thus there is no scope for adverse selection in the typical sense of worker ability differences.

\footnotetext{
${ }^{14}$ As noted above in our analysis of the negative incentive effect, effort levels in one-shot interactions are also higher in T-Barrier than in T-Baseline, and significantly so. With the exception of trades occurring in period 18, where there is no potential for being re-hired, these one-shot interactions can also be interpreted as probation periods, albeit ones that were unsuccessful. We estimate an interval regression where the dependent variable is worker effort levels in one-shot interactions, excluding trades in period 18, and find that effort is higher in T-Barrier than in T-Baseline: the difference in effort levels is $0.879(p<0.044$; robust s.e., clustering on session). This behavior is consistent with the existence of a heterogeneous population of types and the fact that individuals understand this, and therefore attempt to signal their good characteristics with high effort during the probation period.

${ }^{15}$ It turns out that in T-Barrier and T-Baseline, the number of private-offer contracts in long-term relationships in period 18 is exactly the same, so the difference in significance levels does not simply reflect different number of observations.
} 
Result 2: In a market with wage contracts dismissal barriers there is a probation period effect, such that workers reduce effort sharply as soon as the firm triggers dismissal barriers by re-hiring the worker beyond the initial contract. The variance of effort also increases. In the absence of dismissal barriers the opposite pattern occurs. Dismissal barriers also have an additional, positive incentive effect, such that the level of effort in the probation period is even higher than in a market without dismissal barriers.

Although firms face a distribution of worker types, and thus uncertainty about the outcome of entering a long-term relationship, the fact that on average performance suffers is predicted to make firms less likely to enter relationships in the first place. Consistent with the prediction of relationship avoidance we find that 58 percent of all contracts were in oneshot interactions in T-Barrier, compared to 48 percent in T-Baseline. Even more tellingly, we observe 23 percent of all firms in T-Barrier pursuing a strategy of strict relationshipavoidance, never making two private offers in a row to the same worker, during the entire game. This contrasts with only 9 percent of firms exhibiting this strategy in T-Baseline where dismissal barriers are absent. Put another way, the probability that a firm has never been in a long-term relationship as of market period $t$ is consistently higher in T-Barrier than in T-Baseline. We estimate a Cox proportional hazard model, and find that this survival probability is higher in T-Barrier compared to T-Baseline. This difference is only marginally significant overall ( $p<0.07$; robust s.e., clustering on session), reflecting the fact that the survival probabilities are close to 1 in both treatments for the first few market periods; in general long-term relationships do not form until after the first few market periods, during which firms appear to engage in a process of search. Considering market periods beyond period 5, however, the survival probability decreases sharply in T-Baseline whereas the decline 
is slower in T-Barrier, leading to a large difference that is statistically significant at the five percent level ( $p<0.043$; robust s.e., clustering on session).

The barrier institution prevents firms from dismissing workers, which makes it less likely that relationships that do form will break up. This latter tendency is reinforced by the fact that workers essentially never quit once they are protected by dismissal barriers. Workers opt out of a relationship protected by dismissal barriers in only 3 out of 283 such contracts, which is understandable given that in T-Barrier worker earnings are about 48 percent higher on average in long-term relationships than in one-shot interactions. It turns out that the rate of turnover, measured as the average length of a relationship, is essentially the same in T-Barrier and T-Baseline: 5.99 periods versus 5.89. Thus, the resulting stability of long-term relationships happens to just offset the tendency for firms to avoid relationships.

Figure 5 shows that dismissal barriers change the distribution of relationship lengths in the market. The fractions of relationships in the two most extreme categories, which include one-shot interactions or long-term relationships lasting 14 periods or more, respectively, are higher in T-Barrier than in T-Baseline. The opposite is true for the three intermediate categories of relationship lengths. A Probit regression shows that probability of observing a relationship in one of the two extreme categories is significantly higher in T-Barrier than in T-Baseline ( $p<0.001$; robust s.e., clustering on session).

[Figure 5 about here]

Result 3: In a market with wage contracts, firms are more reluctant to enter long-term relationships in the presence of the dismissal barrier institution. They also cannot terminate relationships, and as a consequence the distribution of relationship lengths in the market 
becomes more bi-modal at the extremes, with more one-shot interactions but also more very long relationships.

4.3. Dismissal Barriers and Bonus Pay. In T-Barrier-Bonus, we add the option for firms to pay bonuses. For bonus pay to serve as an incentive device, firms must credibly reward worker effort with bonus payments. Figure 6 shows that bonus payments are in fact strongly increasing in worker performance, and thus that bonus payments are credible. We also regressed actual bonus payments in period $t$ on worker effort levels in $t$ (interval regression), and found that the relationship between effort and bonus payments is positive and highly statistically significant, controlling for wages, desired effort, and a time trend $(p<0.001$; robust s.e., clustering on session $)$.

[Figure 6 about here]

With bonus pay serving as a credible incentive device, firms have a way to at least partially circumvent the negative incentive effect created by dismissal barriers. Figure 2 shows that, indeed, worker effort levels in long-term relationships are consistently much higher in $\mathrm{T}$ Barrier-Bonus than in T-Barrier (average effort is 8.2 rather than 5.5), and achieve a level very close to what is observed in T-Baseline. Columns (3) and (4) of Table 3 indicate that the difference in effort levels is positive and statistically significant when comparing T-BarrierBonus to T-Barrier, controlling for other variables relevant for effort. Columns (5) and (6) confirm that effort levels in T-Barrier-Bonus are not significantly different from effort levels in T-Baseline. Thus, the option to pay bonuses allows firms to undo the negative effects of dismissal barriers. As shown in Figure 3, bonus pay also undoes much of the negative impact of dismissal barriers on market efficiency. Efficiency in T-Barrier-Bonus is 
substantially above that in T-Barrier, by about 10 percentage points, or an increase of 20 percent (Mann-Whitney; $p<0.055)$. On the other hand efficiency is only about 1 percentage point, or 2 percent, lower than efficiency in T-Baseline, and the difference is not statistically significant (Mann Whitney; $p<0.87$ ).

Given that the negative incentive effect of dismissal barriers is largely neutralized by bonus pay, effort dynamics are predicted to be more similar to those observed in T-Baseline. Figure 4 supports this prediction. The median effort level increases after the probation period, and variance decreases, similar to what is observed in T-Baseline. The level of effort in the initial period of relationships is also similar to that in T-Baseline, consistent with bonus pay reducing the incentive for workers to entice firms into relationships. Columns (3) and (4) of Table 4 reveal that the probability of a drop in effort is significantly lower in T-Barrier-Bonus than in T-Barrier, and Columns (5) and (6) show that the probability of a drop in effort in T-Barrier-Bonus is not statistically different from in T-Baseline.

While firms have less reason to avoid relationships in T-Barrier-bonus, because bonus pay helps solve the incentive problem, bonus pay also provides a substitute for relational incentives, and thus firms may be less interested in entering relationships for this reason. The fraction of firms who never enter a long-term relationship in T-Barrier-Bonus is 19 percent, somewhat lower than in T-Barrier where the fraction is 24 percent, but substantially above the 9 percent observed in T-Baseline. The survival probability of never having entered a relationship also indicates that firms in T-Barrier-Bonus are more prone to avoid relationships than firms in T-Baseline. A Cox mixed proportional hazard model shows that the survival probability is significantly higher than in T-Baseline $(p<0.026$; robust s.e., clustering on session). Compared to T-Barrier, the survival probability is higher but not significantly 
different ( $p<0.79$; robust s.e., clustering on session). Thus, the tendency to avoid relationships is similar to in T-Barrier, despite the lack of a strong negative incentive problem. This finding is consistent with bonus pay changing the way that firms enforce contracts, such that they substitute away from relational incentives to one-shot interactions and the use of bonus incentives. To attribute this change to the effect of bonus pay, however, requires our fourth treatment, T-Bonus, where we observe the impact of bonus pay without the confounding effect of dismissal barriers. We turn to this comparison in the next section.

Result 4: The presence of bonus pay strongly affects the impact of the dismissal barrier institution, eliminating both the negative incentive effect and probation period effect. Relationship initiation, however, remains altered relative to T-Baseline, with firms being less likely to enter long-term relationships.

\subsection{Impact of Bonus Pay in the Absence of Dismissal Barriers. In T-Bonus firms} have the option to pay bonuses, but there is no dismissal institution in the market. This allows us to isolate the impact of bonus pay per se on contract enforcement policies and market outcomes.

If bonus pay and relationships are substitutes in the contract enforcement policies of firms (which would help explain the low rate of relationship formation in T-Barrier-Bonus), then introducing bonus pay should lead to fewer and shorter long-term relationships, compared to a market where labor contracts are restricted to fixed wages. In fact, 17 percent of firms never try to enter a long-term relationship in T-Bonus, substantially larger than the 9 percent observed in T-Baseline. A Cox proportional hazard model tells a similar story, showing that the survival probability for never having entered a long-run relationship is higher in T-Bonus than in T-Baseline, with the difference becoming statistically significant considering periods 
beyond 5 ( $p<0.018$; robust s.e., clustering on session). The average length of a relationship in T-Bonus is 2.2, shorter than in T-Baseline or any of the other treatments. Figure 5 shows that the distribution of relationship lengths is not bi-modal in T-Bonus, as in the other treatments, but rather has a single mode in the category of one-shot interactions and the next highest fraction in the category of relationships lasting only 2 to 5 periods. In other words, bonus pay leads to a leftward shift in the distribution, away from longer relationships. For example, a Probit regression shows that the probability of observing a relationship in the longest length category of 14 or more is significantly lower in T-Bonus than in T-Baseline $(p<0.048$; robust s.e., clustering on session $)$. These findings indicate that bonus pay and relational incentives are in fact substitutes, and helps explain why there is a relatively low rate of relationship formation in T-Barrier-Bonus, despite the lack of a negative incentive effect in long-term relationships. While the introduction of bonus pay neutralizes most of the effects of dismissal barriers, it leaves contract enforcement policies fundamentally changed by providing an alternative strategy for contract enforcement.

T-Bonus also provides a useful counter-factual for T-Barrier-Bonus, helping disentangle the impact of dismissal barriers from the effect of bonus pay on the strategic position of workers and firms. In particular, although firms achieve a high level of worker performance in long-term relationships in T-Barrier-Bonus, comparable to in T-Bonus (see Figure 2), the lack of firing threat caused by dismissal barriers would seem to weaken the strategic position of firms. Figure 6 shows that in fact firms in T-Barrier-Bonus pay higher bonuses compared to firms in T-Bonus, to achieve the same level of performance, especially at higher effort levels. In a regression of actual bonus payment on worker effort, the wage, desired effort, a time trend, and a dummy variable for T-Barrier-Bonus (omitted category T-Bonus), the treatment dummy is positive and significant ( $p<0.046$; robust s.e., clustering on session), 
indicating that for a given wage and effort, firms must pay a higher bonus when dismissal barriers are present in the market. This can also be seen by looking at total rents offered to workers in a given market period, calculated in the same way as in the initial analysis of T-Baseline above. Workers earn larger rents in T-Barrier-Bonus than in T-Bonus, in every market period. ${ }^{16}$ Thus, although bonus pay allows firms to largely circumvent the negative incentive effect of dismissal barriers in T-Barrier-Bonus, dismissal barriers still impose a cost on firms. Put another way, the availability of firing threat allows firms to achieve the same level of worker performance with lower bonuses and lower offered rents.

Recent studies have compared the efficiency of bonus versus wage contracts in one-shot interactions, and found that bonus contracts are much superior (e.g., Fehr, Klein, and Schmidt (2007)), which raises the question how bonus contracts fare relative to wage contracts in a setting with repeated interactions. The difference we find is positive but relatively small: aggregate efficiency is 68.54 percent of maximum in T-Bonus compared to 63.86 in T-Baseline (see also Figure 3). One explanation for the relatively good performance of wage contracts is that in a setting with repeated interactions firms can employ firing threat as an incentive device, whereas in one-shot settings the only reason for a worker to perform under a fixed wage contract is fairness preferences.

Result 5: Bonus pay causes firms to substitute away from relational incentives in their contract enforcement policies. Although bonus pay allows firms to offset negative incentive effects of dismissal barriers, dismissal barriers still impose a cost on firms by requiring firms to pay a higher bonus and offer higher rents for a given level of effort. The benefits of bonus pay per se for market efficiency, relative to efficiency wage contracts, is decreasing over time.

\footnotetext{
${ }^{16}$ Taking the average worker rent from being employed in a given session as one independent observation, rents offered by firms in sessions for the T-Barrier-Bonus treatment are significantly higher than those offered by firms in the T-Bonus treatment (Mann-Whitney; $\mathrm{p}<0.007$ ). Detailed results available upon request.
} 


\section{DisCUSSION}

This paper explores how the complex interplay between contract enforcement behaviors and embedding institutions determines market outcomes. With incomplete contracts and repeated interactions, firing threat is crucial for market efficiency, and dismissal barriers worsen performance by hindering this mechanism and by discouraging relationship formation in the first place. Allowing for greater flexibility in contractual instruments, in the form of bonus pay, undoes the effects of dismissal barriers, while leaving contract enforcement strategies fundamentally changed.

Our paper is also complementary to the empirical literature that studies dismissal barriers in the form of employment protection legislation (EPL). Our results show that the impact of dismissal barriers depends crucially on details of the institutional environment. This is consistent with the empirical literature, which sometimes finds zero and other times finds moderate effects of EPL on various types of outcomes (e.g., Lazear (1990), Nickell (1997), Autor, Donohue, and Schwab (2006), MacLeod and Nakavachara (2007)). Furthermore, our findings highlight a specific institutional feature that is relevant for whether dismissal barriers have a strong or weak effect on market performance, namely flexibility of the labor contract. In the spirit of the Coasian intuition articulated by Lazear (1990), we find that giving parties additional contractual instruments allows them to contract around the negative effects of dismissal barriers. As noted by Krueger (1991), a key challenge for assessing the impact of EPL in the field is that the law change itself might be correlated with other factors that are related to economic performance. ${ }^{17}$ In this regard our experimental approach is also useful, because variation in institutions is clearly exogenous. Finally, our results are supportive of other field evidence on specific impacts of EPL. Although measuring shirking in the field is

\footnotetext{
${ }^{17}$ See Holland (1986) for an excellent review of the issues.
} 
difficult, Ichino and Riphan (2005) find evidence of a probation effect similar to ours: worker absenteeism sharply increases when workers are re-hired beyond the probation period for employment protection legislation in Italy. Other studies find a positive correlation between the strength of employment protection legislation and firms' usage of temp agency workers as opposed to long-term contracts (see, e.g., Autor (2003), and Cahuc and Postel-Vinay (2002)), which is in line with the strategic behavior we observe among firms. 


\section{REFERENCES}

Akerlof, G. A. (1982, November). Labor exchange as partial gift exchange. Quarterly Journal of Economics 97(4), 543-69.

Akerlof, G. A. and J. Yellen (1990). The fair wage- effort hypothesis and unemployment. Quarterly Journal of Economics 105, 255-283.

Autor, D. H. (2003). Outsourcing at will: The contribution of unjust dismissal doctrine to the growth of employment outsourcing. Journal of Labor Economics 21(1), 1-42.

Autor, D. H., J. J. Donohue, and S. J. Schwab (2006, May). The costs of wrongful-discharge laws. Forthcoming Review of Economics and Statistcs 88(2), 211-231.

Baker, G., R. Gibbons, and K. J. Murphy (1994, November). Subjective performance measures in optimal incentive contracts. The Quarterly Journal of Economics 109(439), 1125-1156.

Bowles, S. (1985). The production process in a competitive economy: Walrasian, neohobbesian, and marxian models. Journal of Economic Literature 75, 16-36.

Brown, M., A. Falk, and E. Fehr (2004, May). Relational contracts and the nature of market interactions. Econometrica $72(3), 747-780$.

Bull, C. (1987). The existence of self-enforcing implicit contracts. Quarterly Journal of Economics 102, 147-159.

Cahuc, P. and F. Postel-Vinay (2002, February). Temporary jobs, employment protection and labor market performance. Labour Economics 9(1), 63-91.

Fehr, E. and A. Falk (1999, February). Wage rigidity in a competitive incomplete contract market. Journal of Political Economy 107(1), 106-34.

Fehr, E. and S. Gächter (2000, Summer). Fairness and retaliation: The economics of reciprocity. Journal of Economic Perspectives 14(3), 159-181. 
Fehr, E., S. Gächter, and G. Kirchsteiger (1997, July). Reciprocity as a contract enforcement device: Experimental evidence. Econometrica 65(4), 833-860.

Fehr, E., G. Kirchsteiger, and A. Riedl (1993). Does fairness prevent market clearing? an experimental investigation. Quarterly Journal of Economics 108, 437-460.

Fehr, E., A. Klein, and K. Schmidt (2007, January). Fairness and contract design. Econometrica 75(1), 121-154.

Fischbacher, U. (2007, June). z-tree: Zurich toolbox for ready-made economic experiments. Experimental Economics 10(2), 171-178.

Fudenberg, D. and E. Maskin (1986). The folk theorem in repeated games with discounting or with incomplete information. Econometrica 54, 533-556.

Holland, P. W. (1986). Statistics and causal inference. Journal of the American Statistical Association 81 (396), 945-960.

Ichino, A. and R. T. Riphan (2005, March). The Effect of Employment Protection on Worker Effort - A Comparison of Absenteeism During and After Probation. Journal of the European Economic Association 3(1), 120-143.

Klein, B. and K. Leffler (1981). The role of market forces in assuring contractual performance. Journal of Political Economy 89, 615-641.

Kreps, D. M., P. Milgrom, J. Roberts, and R. Wilson (1982). Rational cooperation in the finitely repeated prisoners-dilemma. Journal of Economic Theory 27(2), 245-252. Article.

Krueger, A. B. (1991, July). The evolution of unjust-dismissal legislation in the united states. Industrial and Labor Relations Review 44(4), 644-60.

Lazear, E. P. (1990, August). Job security provisions and employment. Quarterly Journal of Economics 105(3), 699-726. 
Levin, J. (2003). Relational incentive contacts. American Economic Review 93(3), 835857.

MacLeod, W. B. (2007, May). Can contract theory explain social preferences? American Economic Review $97(2)$.

MacLeod, W. B. and J. M. Malcomson (1989, March). Implicit contracts, incentive compatibility, and involuntary unemployment. Econometrica 57(2), 447-480.

MacLeod, W. B. and J. M. Malcomson (1998, June). Motivation and markets. American Economic Review 88(3), 388-411.

MacLeod, W. B. and V. Nakavachara (2007, June). Legal default rules: The case of wrongful discharge laws. Economic Journal 117, F1-F62.

Mincer, J. (1962). On-the-job training: Cost, returns and some implications. Journal of Political Economy 70(5), 50-79.

Nickell, S. (1997, Summer). Unemployment and labor market rigidities: Europe versus north america. Journal of Economic Perspectives 11 (3), 55-74.

Pearce, D. G. and E. Stacchetti (1998, April). The interaction of implicit and explicit contracts in repeated agency. Games and Economic Behavior 23(1), 75-96.

Shapiro, C. and J. E. Stiglitz (1984, June). Equilibrium unemployment as a worker discipline device. American Economic Review 74 (3), 433-444.

Telser, L. G. (1980, Jan.). A theory of self-enforcing agreements. Journal of Business 53(1), 27-44. FLA 00219398 University of Chicago Press Copyright 1980 The University of Chicago Press.

Williamson, O. E., M. L. Wachter, and J. E. Harris (1975, Spring). Understanding the employment relation: The analysis of idiosyncratic exchange. Bell Journal of Economics $6(1), 250-278$. 


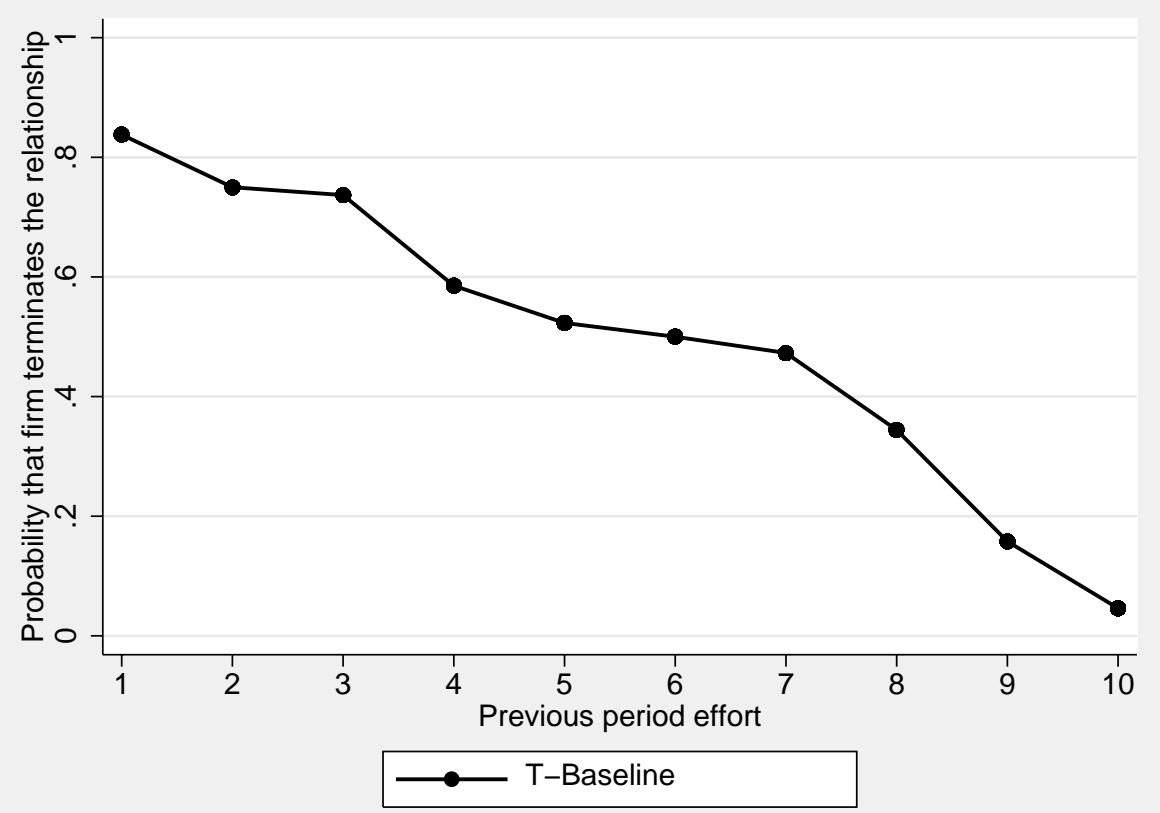

Figure 1: Average probability that a firm chooses not to re-hire a worker with a private offer, as a function of worker performance in the previous period. 


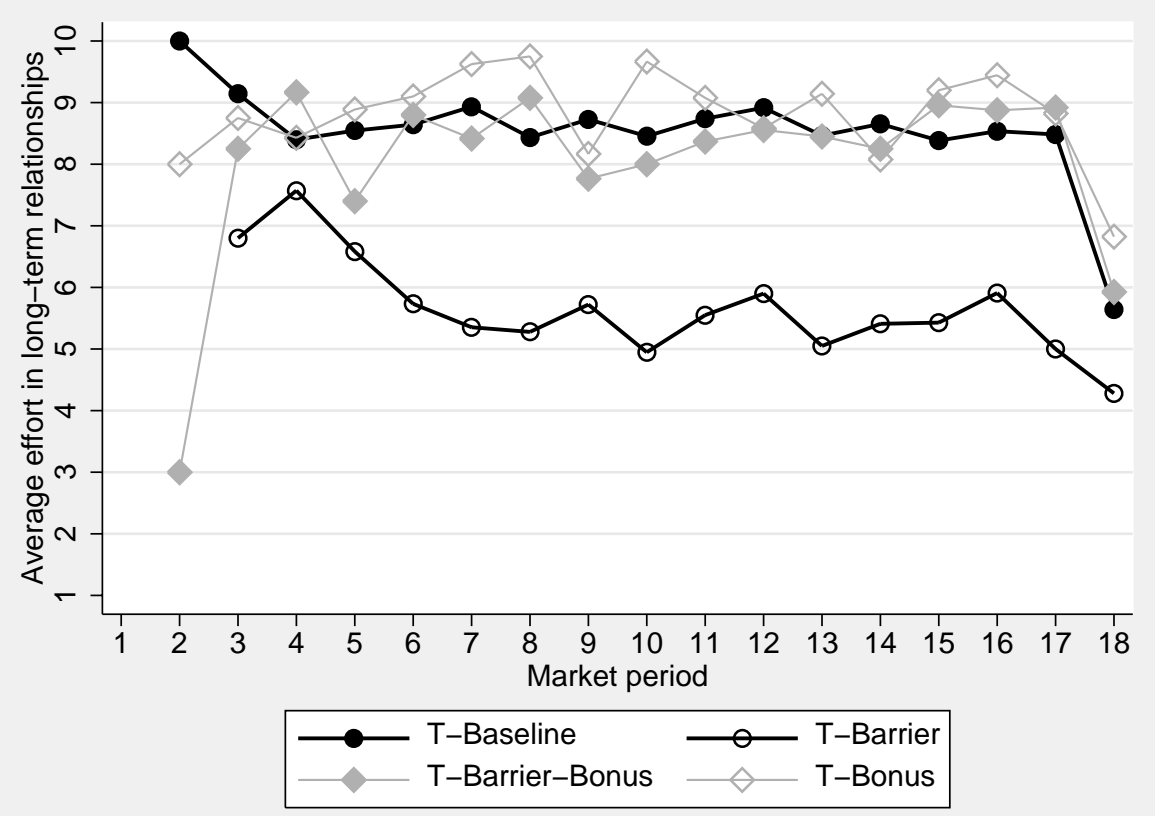

Figure 2: Average worker effort levels in long-term relationships. A long-term relationship is defined as the same firm and worker engaging in a sequence of at least two consecutive, private offer contracts with each other. 

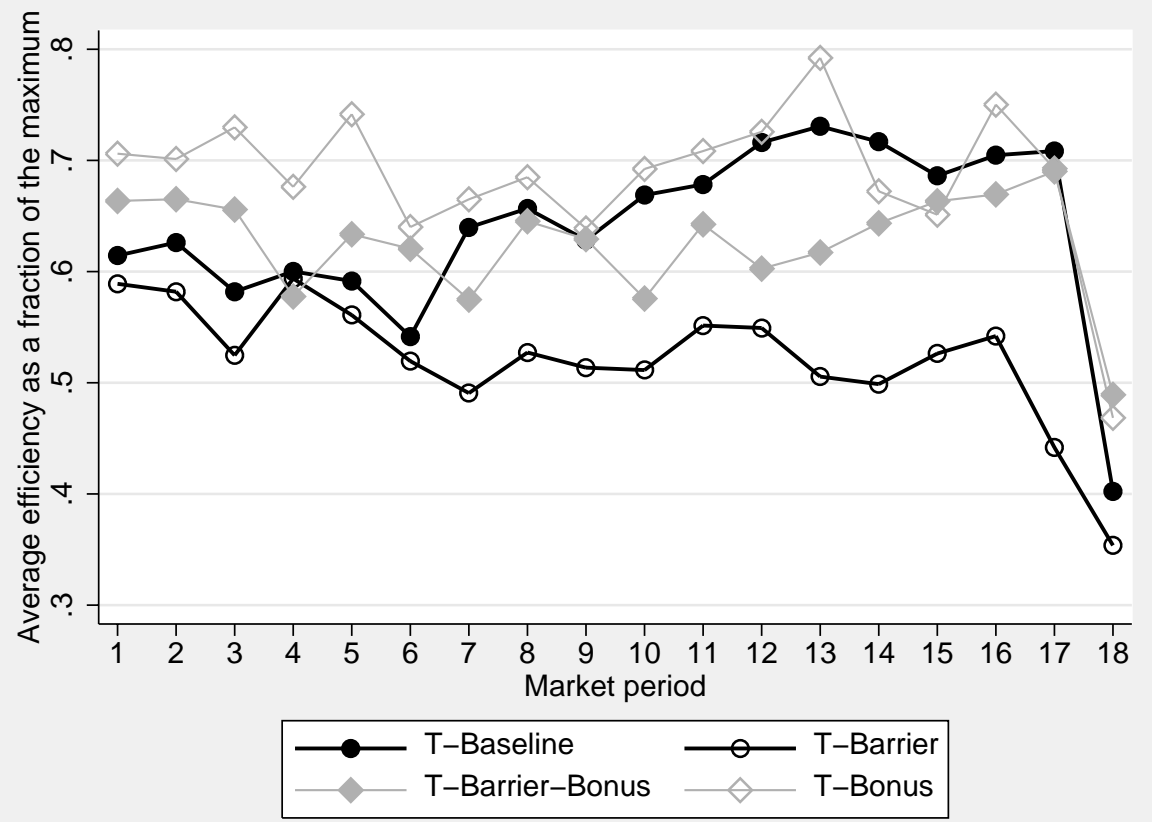

Figure 3: Average market efficiency (total economic surplus) in a given period, as a fraction of maximum possible efficiency. 


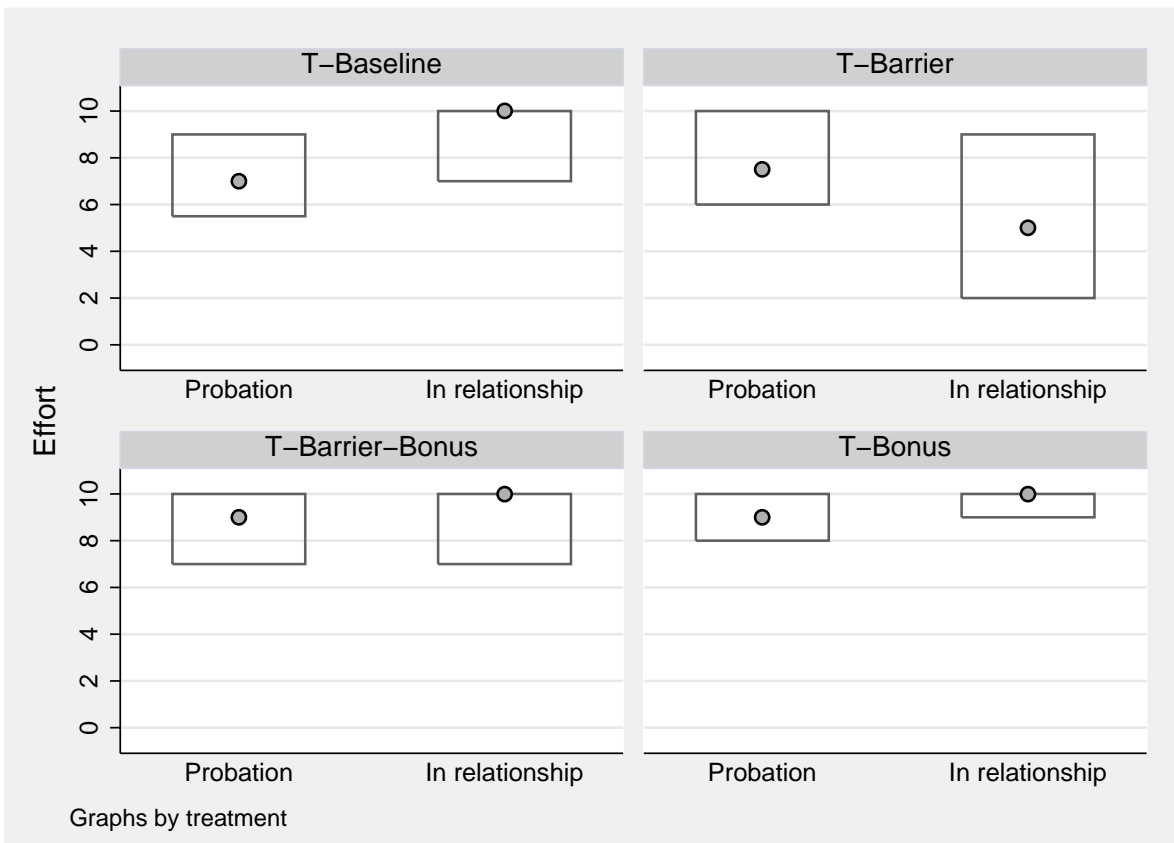

Figure 4: Boxes indicate interquartile ranges (25th to 75 th percentile) for the distributions of worker effort choices. Circular markers indicate median effort levels. The sample is restricted to workers who are ultimately rehired after the probationary period, so effort distributions in the probation period and later relationship periods are both based on the same workers. 


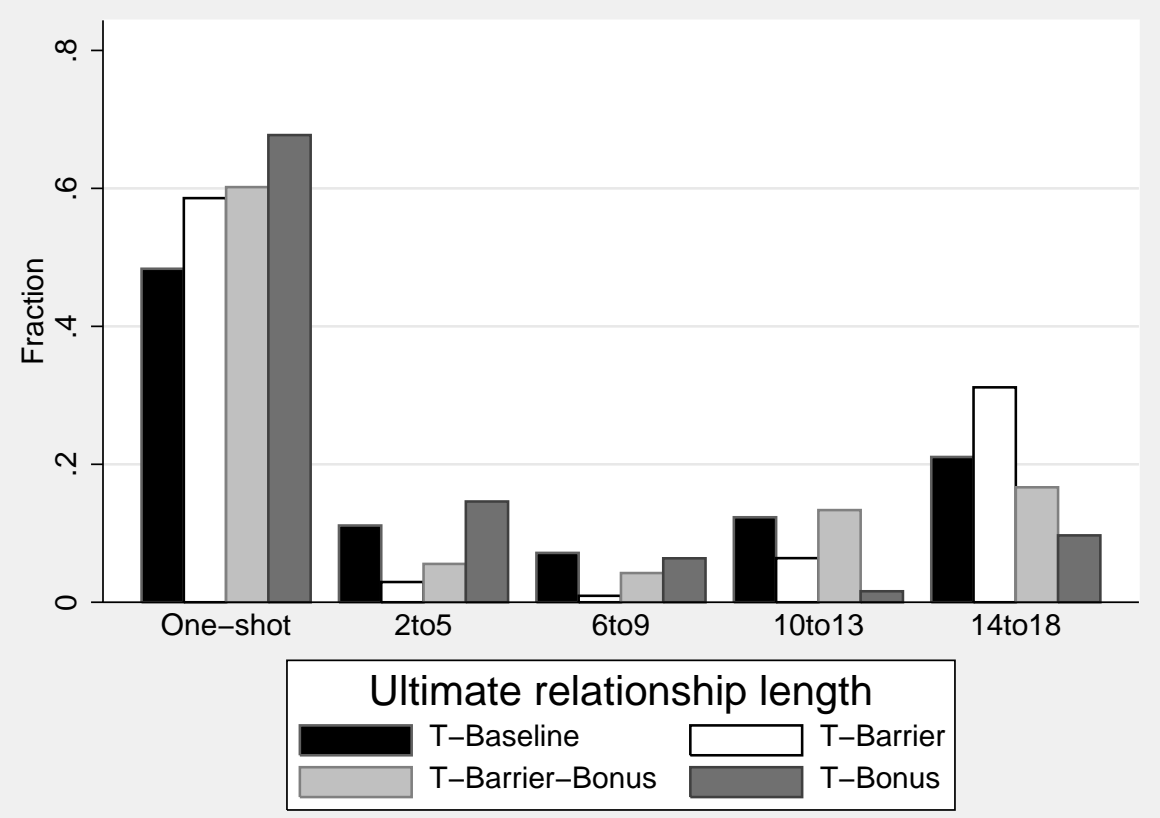

Figure 5: The distribution of relationship lengths, where a relationship is defined as a sequence of consecutive private offer contracts between the same worker and firm. The category one-shot also includes public offer contracts, which occurred when firms made an offer available to all workers, rather than targeting a specific worker. 


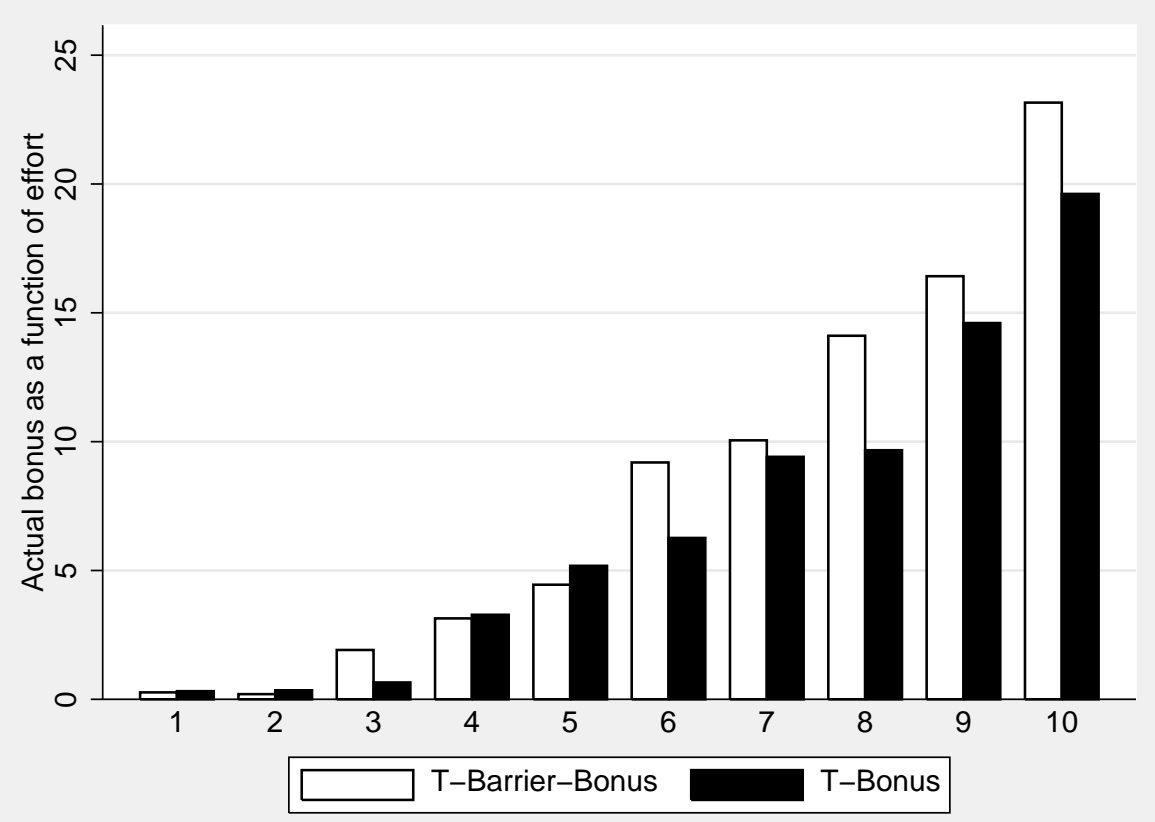

Figure 6: The bonus paid by firms (after observing worker performance) as a function of worker performance. 


\begin{tabular}{lccccc}
\hline \hline & Contract Form & Distinguishing & Features & Sessions & Subjects \\
\hline & & Dismissal barrier & Bonus pay & \\
T-Baseline & $\{w, \tilde{e}\}$ & No & No & 6 & 102 \\
T-Barrier & $\{w, \tilde{e}\}$ & Yes & No & 6 & 102 \\
T-Barrier-Bonus & $\{w, \tilde{e}, \tilde{b}\}$ & Yes & Yes & 6 & 102 \\
T-Bonus & $\{w, \tilde{e}, \tilde{b}\}$ & No & Yes & 6 & 102 \\
& & & Total: & 24 & 408 \\
\hline \hline
\end{tabular}

Table 1: Overview of treatments. 


\begin{tabular}{lcccccccccc} 
Effort & 1 & 2 & 3 & 4 & 5 & 6 & 7 & 8 & 9 & 10 \\
\hline Cost & 0 & 1 & 2 & 4 & 6 & 8 & 10 & 12 & 15 & 18
\end{tabular}

Table 2: Effort cost schedule. 


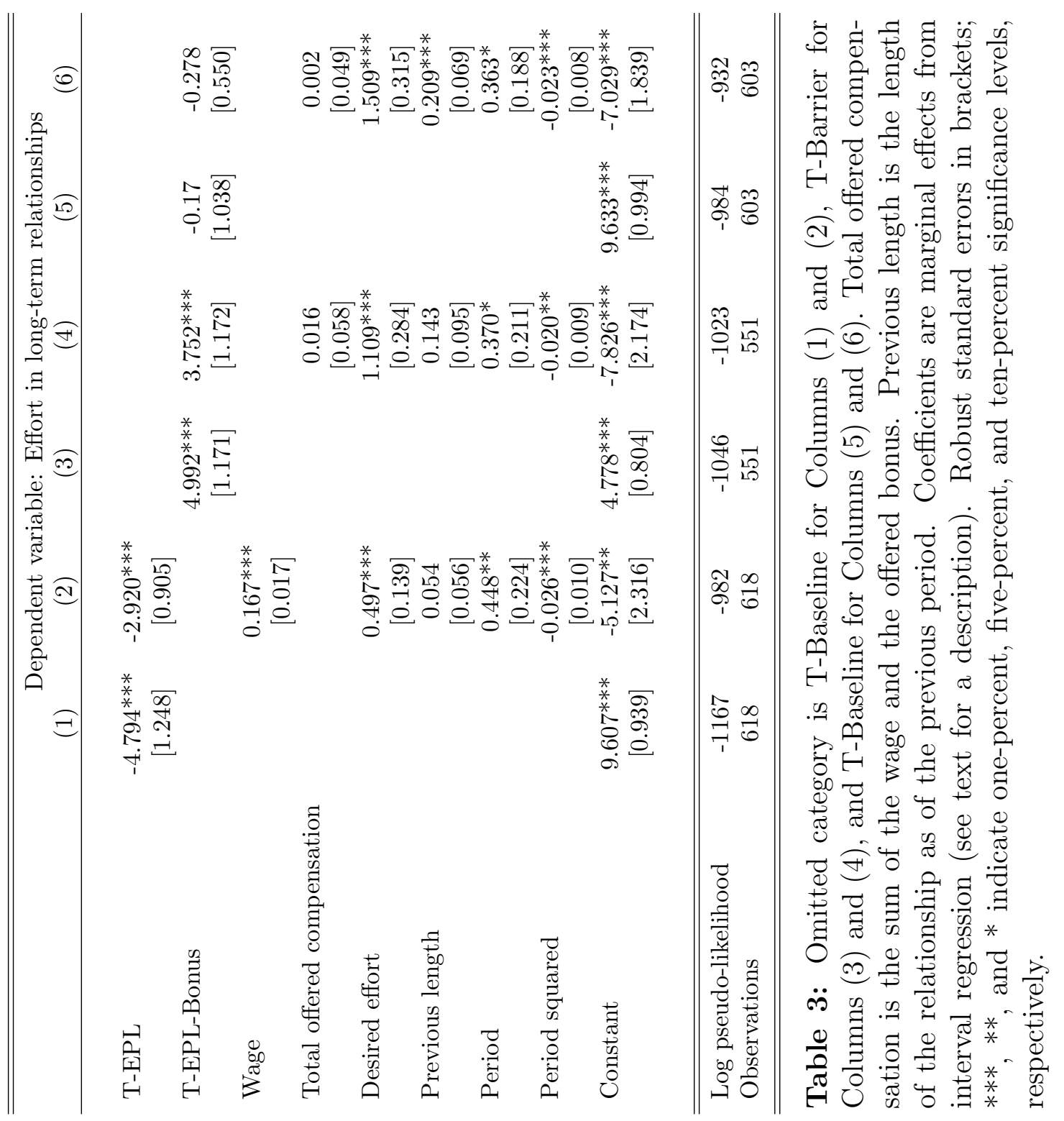




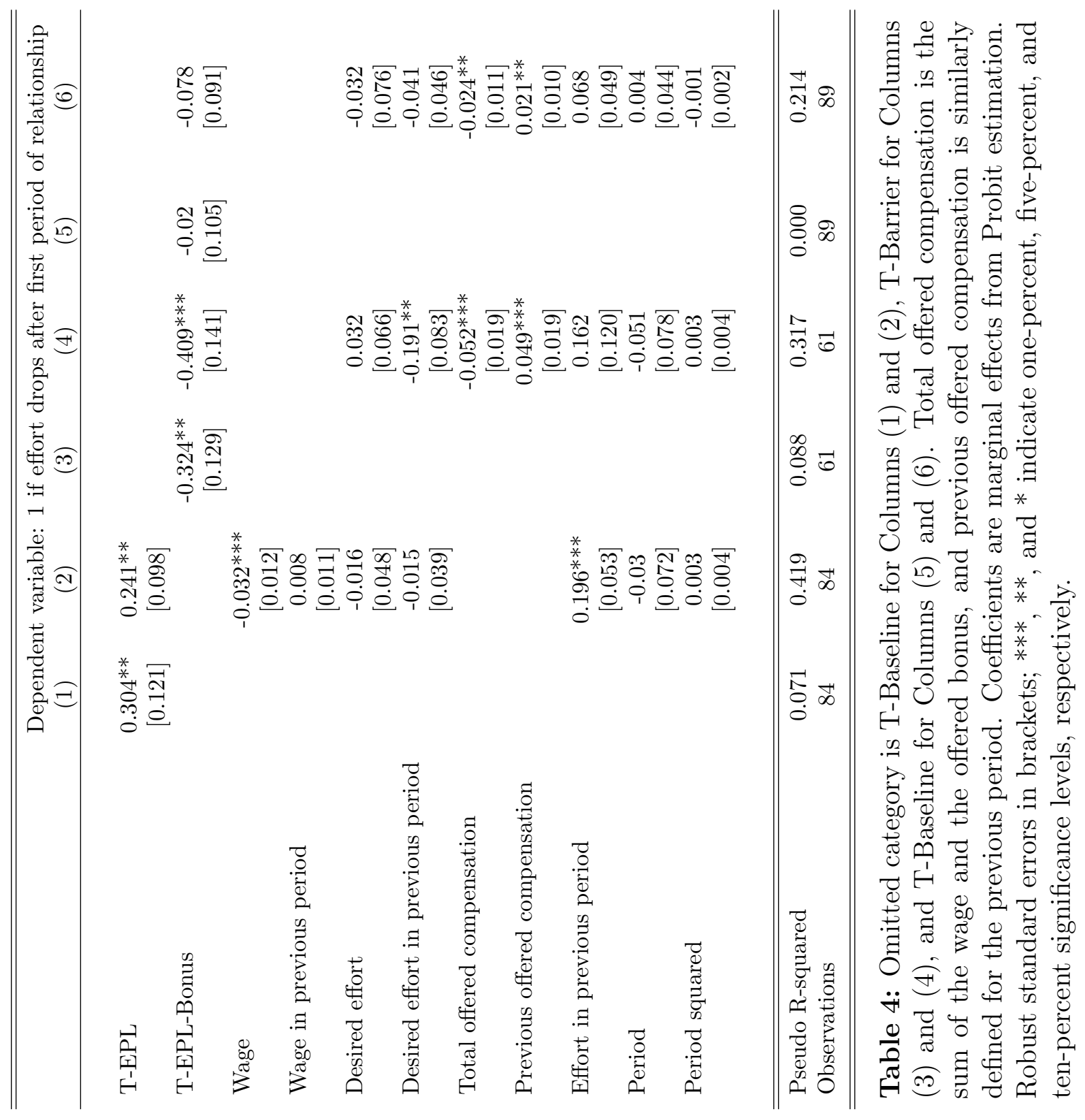




\section{APPENDIX: INSTRUCTIONS}

In the following we present representative instructions, in this case for a worker (seller) from the treatment T-Barrier. Instructions for firms (buyers) and for participants in other treatments are exactly the same, except for including explanation of the option for firms to pay bonuses in the case of T-Barrier-Bonus and T-Bonus, or excluding the final section explaining the dismissal barrier institution in the case of T-Bonus and T-Baseline.

\section{Instructions for Sellers}

You are now taking part in an economic experiment. Please read the following instructions carefully. Everything that you need to know to participate in this experiment is explained below. Should you have any difficulties in understanding these instructions please notify us. We will answer your questions at your cubicle.

At the beginning of the experiment you will receive an initial sum of 8 Euro. During the course of the experiment you can earn a further amount of money by gaining points. The amount of points that you gain during the experiment depends on your decisions and the decisions of other participants.

All points that you gain during the course of the experiment will be exchanged into Euro at the end of the experiment. The exchange rate will be:

$$
1 \text { point }=4 \text { Cents }
$$

\section{At the end of the experiment you will receive the sum of money that you earned} during the experiment in addition to your 8 Euro initial sum.

The experiment is divided into periods. In each period you have to make decisions which you will enter in a computer. There are 18 periods in all.

Please note that communication between participants is strictly prohibited during the experiment. In addition we would like to point out that you may only use the computer functions which are required for the experiment. Communication between participants and unnecessary interference with computers will lead to exclusion from the experiment. In case you have any questions we shall be glad to assist you.

Prior to the experiment the 17 participants were divided into 2 groups: buyers and sellers. In this experiment there are 10 sellers and 7 buyers. 
You shall be a seller for the entire course of the experiment. All participants have received an identification number, which they will keep for the entire experiment. Your identification number is stated on the documentation sheet in front of you.

\section{An Overview of the Experiment Procedures}

In each period of the experiment every buyer can trade a product with one seller. The seller earns a profit through the trade when he sells the product at a price that exceeds his production costs. The buyer earns a profit through the trade when the price he pays for the product is less than what it is worth to him. How high the production costs are for the traded product, and how much it is worth to the buyer, depends on the quality of the product.

The experiment lasts 18 periods. In each period the procedures are as follows:

1. Each period commences with a trading phase, which lasts 150 seconds. During this phase buyers can submit trade offers, which can be accepted by sellers.

When submitting an offer a buyer has to specify three things:

- which price he offers to pay,

- which product quality he desires,

- and finally, which seller he wants to submit the offer to. Hereby, buyers can submit two types of offers; private offers and public offers. Private offers are submitted to one seller only and can only be accepted by that seller. Public offers are submitted to all sellers and can be accepted by any seller.

Buyers can submit as many offers as they like in each period. Submitted offers can be accepted constantly. Each buyer and each seller can only enter one trade agreement in each period. As there are 10 sellers and 7 buyers, several sellers will not trade in each period.

2. Following the trading phase each seller who has entered a trade agreement determines which quality of product he will supply to his buyer. Hereby, the seller is not obliged to supply the product quality desired by his buyer.

Please note: If the same buyer has made private offer to the same seller in two consecutive periods, and if the seller has accepted these two offers, the seller enjoys the "right to get an offer". This means that the buyer has to make this seller an offer in the next period. If the seller accepts, this "right to get an offer" continues to exist. If he rejects, the buyer is free to make an offer to any seller.

Once every seller has chosen which product quality to supply, incomes gained by each participant in that period are determined and reported on the screen. After this the next 
period commences. The points gained from all 18 periods will be summed up at the end of the experiment, exchanged into Euros and paid together with your initial sum of money in cash.

\section{Procedures in Detail}

There are 7 buyers and 10 sellers in the experiment. You are a seller for the entire course of the experiment. During the experiment you will enter your decisions on the computer. In the following we describe in detail how you can make your decisions in each period.

\section{The Trading Phase}

Each period commences with a trading phase. During the trading phase each buyer can enter into a trading agreement with one seller. In order to do this the buyers can submit trade offers to the sellers. As a seller you can accept one of the offers submitted to you in each period. During the trading phase you will see the following screen:

\section{Seller trading screen}

- In the top left corner of the screen you will see the current period of the experiment. In the top right corner of the screen you will see the time remaining in this trading phase, displayed in seconds. The trading phase in each period lasts 150 seconds. When this time is up the trading phase is over. Hereafter, no further offers can be submitted or accepted for this period.

- Once you see the above screen displayed the trading phase commences. As a seller you can now accept offers, which buyers have submitted to you. There are two types of offers which you can accept:

\section{- Private offers to you}

Each buyer has the opportunity to submit private offers to you. You alone will be informed of these offers and you alone can accept them. No other seller or buyer is informed of these offers. If you receive private offers, they will appear on the left side of your screen, below the title "private offers to you". The offer of a buyer will contain the following information: the identification number of the buyer who submitted the offer, the price which he offers for the product, and which product quality he desires. If you want to accept a private offer, you click first on the respective row in which the offer is displayed. When you do this, the offer will be highlighted. If you are sure you want to accept the offer you then click on the button "accept" which is situated in the bottom left corner of the screen. As long as you do not click "accept" you can alter your choice. 


\section{- Public offers}

Each buyer also has the possibility to submit public offers. All sellers are informed of these offers and any seller can accept them. If a buyer submits a public offer it will appear on the right side of your screen, below the title "public offers". The offer of a buyer again contains the identification number of the buyer who submitted the offer, the price which he offers for the product and which product quality he desires. This information is also displayed to all other sellers and all buyers. If you want to accept a public offer you follow the same procedures as with private offers. You first click on the respective row in which the offer is displayed. When you are sure that you want to accept the offer you then click on the button "accept" which is situated in the bottom right corner of the screen. As long as you do not click "accept" you can alter your choice.

- As soon as you have pressed the "accept" button you will see which offer you have accepted in the bottom row of your screen.

- Each seller can enter only one trade agreement in each period. Once you have accepted one offer you cannot accept any further offers.

\section{All buyers have to observe the following rules when submitting trade offers:}

- The price offered by the buyer may not be lower than 0 or higher than 100 :

$$
0 \leq \text { price } \leq 100
$$

- The desired quality of the buyer may not be below 1 or higher than 10:

$$
1 \leq \text { desired quality } \leq 10
$$

- As long as no offer has been accepted by a seller, the buyer can make as many public and private offers as he wishes. Each offer submitted by a buyer can be accepted at any time during the trading phase.

- Each buyer can enter only one trade agreement in each period. Once an offer of a buyer has been accepted he will be notified which seller accepted it. As each buyer can enter only one trade agreement in each period all other offers of the buyer will be automatically cancelled. Also, he will not be able to submit any further offers.

- Once all 7 buyers have entered a trade agreement or after 150 seconds have elapsed, the trading phase is over. 
- No buyer is obliged to submit trade offers, and no seller is obliged to accept a trade offer.

\section{Determination of the Product Quality}

- Following the trading phase, all sellers who have entered a trade-agreement then determine which product quality they will supply to their respective buyers. The product quality desired by your buyer is not binding for you as a seller. You can choose the exact quality desired by your buyer, but also a higher or lower product quality. If you have entered a trade agreement during a trading phase, the following screen will appear for you to enter the product quality:

\section{Seller quality choice screen}

In order to choose the actual product quality, you enter the value for the quality in the field "Determine the actual product quality" and press the "ok" button to confirm your choice. As long as you have not pressed "ok" you can alter your choice.

- The product quality that you choose must be an integer between 1 and 10 .

$$
1 \leq \text { actual product quality } \leq 10
$$

\section{How are the incomes calculated?}

\section{Your income:}

- If you have not entered a trade agreement during a trading phase you gain an income of 5 points for that period.

- If you have accepted a trade offer your income depends on the price you accepted and the product quality you chose to deliver. Your income will be calculated as follows:

\section{Your income $=$ Price - production costs}

- Your production costs are higher, the higher the quality of the product you chose to deliver. The production costs for each product quality are displayed in the table below: 


\begin{tabular}{|l|c|c|c|c|c|c|c|c|c|c|}
\hline Quality & $\mathbf{1}$ & $\mathbf{2}$ & $\mathbf{3}$ & $\mathbf{4}$ & $\mathbf{5}$ & $\mathbf{6}$ & $\mathbf{7}$ & $\mathbf{8}$ & $\mathbf{9}$ & $\mathbf{1 0}$ \\
\hline $\begin{array}{l}\text { Production- } \\
\text { cost }\end{array}$ & 0 & 1 & 2 & 4 & 6 & 8 & 10 & 12 & 15 & 18 \\
\hline
\end{tabular}

- Your income is therefore higher, the lower your chosen product quality. Furthermore, your income is higher the higher is the price offered by the buyer.

\section{The income of your buyer:}

- If a buyer does not enter a trade agreement during a trading phase he gains an income of 0 points for that period.

- If one of his trade offers is accepted, his income depends on which price he offered and which product quality was supplied to him. The income of your buyer will be determined as follows:

\section{Income of your buyer $=10 *$ product quality - price}

- As you can see from the above formula the income of your buyer is higher, the higher is the product quality actually supplied by you. At the same time his income is higher, the lower the price he paid for the product.

The income of all buyers and sellers are determined in the same way. Each buyer can therefore calculate the income of his seller and each seller can calculate the income of his buyer. Furthermore, each buyer and seller is informed of the identification number of his trading partner in each period.

Please note that buyers and sellers can incur losses in each period. These losses have to be paid from your initial sum of money or from earnings in other periods.

You will be informed of your income and the income of your buyer on an "income screen". On the screen (see below) the following will be displayed:

- Which buyer you traded with

- Which price he offered

- The desired quality of your buyer

- The product quality supplied by you

- The income of your buyer in this period

- Your income in this period. 
Please enter all the information in the documentation sheet supplied to you. After the income screen has been displayed, the respective period is concluded. Thereafter the trading phase of the following period commences. Once you have finished studying the income screen please click on the "next" button.

The buyers also view an income screen, which displays the above information. They see the ID of their trading partner, the price, desired and supplied product quality as well as both incomes.

\section{"Right to get an offer"-Rule}

There is one more rule to consider. If the same buyer has made two private offers to the same seller in two consecutive periods, and both offers were accepted so that they each lead to a trade agreement, the seller enjoys the "right to get an offer" in the next period. This is the case, e.g., if buyer 1 makes seller 2 private offers, one in period 3 and one in period 4 , which are both accepted by seller 2 . Starting from period 5 , seller 2 then enjoys the "right to get an offer".

The right to get an offer is thus established when a buyer has traded at least twice with the same seller, and if these trades came about through private offers. If trade comes about based on a public offer, the right to get an offer is not established. Thus the buyer himself can decide whether he wants to enter a relationship with or without the right to get an offer.

In other words the "right to get an offer" means that in the next period the buyer must make the seller an offer that is available as soon as soon as the trading phase begins. This offer consists of a price and desired quality. The price must be at least as high as in the previous period.

If the same buyer has offered you two times in a row a private offer, which you accepted, you enjoy the right to get an offer. This means "your" buyer must make you an offer in the next period. In this case the trading phase begins with the following screen.

\section{Modified trading phase screen}

This is the same screen as on page 3 with the only difference that on the upper right corner you now see the offer of your buyer. In addition you also see the other public and private offers, which have been offered to you and the other sellers. You can accept the offer of "your" buyer or any other offer that has been made (private or public) by other buyers.

As long as you have not yet decided, "your" buyer cannot make another offer to you or another seller. This means that you can accept the offer of "your" buyer as long as you have not declined it (and trading time has not yet elapsed). 
Your buyer will be informed about your decision. If you reject his offer or if you accept another buyer's offer, "your" buyer is free to make offers to other sellers. As long as you have not yet decided, all "your" buyer can do is wait and observe the market.

If you accept the offer of "your" buyer, he will also make you an offer in the next period. Only if you reject his offer or if you accept the offer of another buyer, the right to get an offer expires. This means that the right to get an offer can only be terminated by yourself.

An example concerning the right to get an offer: Suppose buyer 1 and seller 2 have traded in periods three and four, based on two private offers. Starting from period 5 seller 2 then enjoys the right to get an offer. This means that buyer 1 has to make seller 2 an offer in the fifth period before the trading period begins. If seller 2 accepts, the relation remains and buyer 1 will make seller 2 an offer also in period 6 . If seller 2 rejects, the relation is terminated and buyer 1 can thereafter make offers to all sellers (public and private).

The experiment will not commence until all participants are completely familiar with all procedures. In order to secure that this is the case we kindly ask you to solve the exercises below.

In addition we will conduct a training trial of the trading phase, so that you can get accustomed to the computer. This trial phase will not be added to the result of the experiment and therefore not remunerated. Following the trial phase we will begin the experiment, which will last for 18 periods.

\section{Exercises}

Please solve the following problems including the solution approach. If you have any questions please ask the experimenter. Wrong answers have no consequences whatsoever.

\section{Problem 1:}

You have not accepted any offer during a trading period. What is your income in this particular period?

\section{Problem 2:}

Your income $=$

You have accepted an offer, containing a price of 60 and a desired quality of 9. You choose an actual quality of 9 . 


$$
\begin{aligned}
& \text { Your income }= \\
& \text { Income of your buyer }=
\end{aligned}
$$

\section{Problem 3:}

You have accepted an offer, containing a price of 60 and a desired quality of 9. You choose an actual quality of 4 .

$$
\begin{aligned}
& \text { Your income }= \\
& \text { Income of your buyer = }
\end{aligned}
$$

\section{Problem 4:}

You have accepted an offer, containing a price of 40 and a desired quality of 2. You choose an actual quality of 5 .

$$
\begin{aligned}
& \text { Your income }= \\
& \text { Income of your buyer }=
\end{aligned}
$$

\section{Problem 5:}

You have accepted an offer, containing a price of 10 and a desired quality of 6 . You choose an actual quality of 6 .

\section{Problem 6:}

Your income $=$

Income of your buyer $=$

Suppose you have accepted a private offer from a particular buyer in period 5. In period 6 you accept a public offer coming from the same buyer. Do you enjoy the right to get an offer starting from period 7 ?

- Yes 